\title{
A Simulation Model for the Risk of Fetal Exposure Originated by the Zika Virus (VIZK)
}

\author{
Dalia M. Muñoz Pizza1, Anibal Muñoz Loaiza1, Oscar A. Manrique Arias', Vanessa Abello Sossa1, \\ Carlos A. Abello Muñoz ${ }^{1}$, Steven Raigosa Osorio', Hans Meyer Contreras', \\ John F. Arredondo Montoya1, Gonzaga Ospina Patiño1, Irma Pérez Contreras², \\ Maria E. Cardenas Perea², Miguel A. Enríquez Guerra², Jesús A. Valdez García² \\ ${ }^{1}$ Grupo de Modelación Matemática en Epidemiología (GMME), Facultad de Educación, Universidad del Quindío, Quindío, Colombia \\ ${ }^{2}$ Facultad de Medicina, Benemérita Universidad Autónoma de Puebla, Puebla, México \\ Email: marcolombia86@hotmail.com,irmpecon86@gmail.com
}

How to cite this paper: Pizza, D.M.M., Loaiza, A.M., Arias, O.A.M., Sossa, V.A., Muñoz, C.A.A., Osorio, S.R., Contreras, H.M., Montoya, J.F.A., Patiño, G.O., Contreras, I.P., Perea, M.E.C., Guerra, M.A.E. and García, J.A.V. (2016) A Simulation Model for the Risk of Fetal Exposure Originated by the Zika Virus (VIZK). Health, 8 , 1178-1186.

http://dx.doi.org/10.4236/health.2016.812121

Received: June 22, 2016

Accepted: August 30, 2016

Published: September 2, 2016

Copyright $\odot 2016$ by authors and Scientific Research Publishing Inc. This work is licensed under the Creative Commons Attribution International License (CC BY 4.0). http://creativecommons.org/licenses/by/4.0/

\begin{abstract}
It is set and analyzed a simulation model based on non-linear ordinary differential equations to interpret the dynamics of the microcephaly incidence caused by the $\mathrm{Zi}$ ka virus in a risk group of pregnant women. This one is induced by a population of men in a reproductive age. Also, some parameters of the model were estimated for an average temperature of $23^{\circ} \mathrm{C}$ and by using the adjusted functions from references [1] [2]. All system simulations were done with the Maple software and parameters values obtained from several sources (estimated, hypothetic, and form literature). It has been found that the application of contraceptive measures impacts the population of sexually active women. As result, the exposure to congenital abnormalities increases, particularly, microcephaly.
\end{abstract}

\section{Keywords}

Model, Microcephaly, Zika Virus, Basic Reproduction Number, Risk Group, Incidence

\section{Introduction}

The Zika virus (ZIKV) is transmitted by mosquitoes of the Flaviviridae family of the Flavivirus gender. These ones are pretty close to the ones that transmit encephalitis, yellow fever, dengue, and virus del Nilo. It was isolated in 1947 from blood of the Rhesus monkey (Macacamulatta) that it was feverish during a study of the yellow fever at the Zika forest in Uganda [3]. Later on, the virus was isolated from an Aedes africanus mosquitoes group in 1948 at the same region of the Zika jungle [4]. The natural cycle of 
ZIKV implies mosquitoes principally from the genders: Aedes, Aedes furcifer, Aedes taylori, Aedes luteocephalus, and Aedes aegypti. The last one is considered the main vector for virus transmission [5]-[7]. ZIKV is transmitted by the infected mosquitoes bite maintaining a zoonotic cycle (disease transmission from animals to humans). In this transmission cycle, humans serve as accidental hosts, however, in areas without primates the humans take the role of primary amplifiers [8]. It is suspected that ZIKV uses the primates as principal agents for their reproduction and transmission. Antibodies were detected in other animal species, including: buffaloes, elephants, goats, and hippopotamus among others. This fact suggests the possibility of multi-species transmission. Furthermore, there exists evidence of sexual transmission in humans [5] [9].

ZIKV infection variates in humans, the most common symptoms are: flu, headache, anorexia, eye ache, general discomfort, myalgia, arthralgia, asthenia, edema and diarrhea, that is to say, the symptomatology is unspecific. All this clinical picture may be confused with the other existent diseases, particularly with the most frequent ones, Dengue and Chikungunya [5] [6] [10] [12]. Even some people could be asymptomatic to this disease.

The ZIKV introduces questions about the possible role of the infection with the microcephaly; actually there are only ecological evidences. Microcephaly is defined as the presence of a cranial perimeter less than a couple of standard deviations for the average age, sex, and gestational age [14]. Investigations suggest an increase in the microcephaly in some states where ZIKV was detected, indicating a possible association between events [13]. The maternal-fetal transmission has been demonstrated in several infections as, Dengue and Nilo fever. Also, this disease may cause premature delivery, birth defects and microcephaly [11].

In the last years it has been observed an increase in the infectious diseases, this is due to the known symptoms as well as the reemerging ones that have appeared with a high incidence because of social, economic and health factors. Such is the case of ZIKV, an endemic virus in some countries of Africa and Asia that has been expanded to other zones [8]. From these facts emerges the importance of mathematical models on the risk of exposition to the ZIKV.

Recently, some reports treating this issue have appeared. Daozhou et al. (2016), have analyzed a mathematical model for the prevention and control of Zika, including the vectorial and sexual transmission, with data of epidemic outbreaks of Brazil, Colombia and the Salvador. From those studies they conclude that the $\mathrm{R}_{0}$ is more sensitive to the bite rate and the natural death rate of the mosquitoes as well as the sexual transmission increases the risk of infection, the epidemic size and extends the outbreak [15]. Nishiura et al. (2016), have estimated the $\mathrm{R}_{0}$ of the ZIKV infection, as an indicator of potential transmission, using data from the South Pacific region [16]. On the other hand, Muñoz et al. (2016) have formulated and analyzed a mathematical model to treat the risk of microcephaly incidence caused by the ZIKV in a pregnant women group [17].

The model proposed in this paper helps to provide information that may help to elaborate effective control strategies, potential scenarios and transmission mechanisms 
of the virus.

\section{The Model}

It is proposed a simulation model based in non-linear ordinary differential equations to describe the dynamics of pregnant women that are susceptible to get infected by ZIKV and may present fetal microcephaly induced by this virus. The variables of the model are described in Table 1 and the parameters in Table 2.

Table 1. Variables and initial populations of the model.

\begin{tabular}{|c|c|c|}
\hline Variable & Description & Initial populations \\
\hline$x_{1}$ & $\begin{array}{l}\text { The susceptible and sexually active women's } \\
\text { population }\end{array}$ & $x_{1}(0)=400000$ \\
\hline$x_{2}$ & The susceptible pregnant women's population & $x_{2}(0)=10$ \\
\hline$x_{3}$ & ZIKV positive pregnant women's population & $x_{3}(0)=0$ \\
\hline$x_{4}$ & $\begin{array}{l}\text { Infected pregnant women with no development of } \\
\text { microcephaly }\end{array}$ & $x_{4}(0)=0$ \\
\hline$x_{5}$ & Infected women's population & $x_{5}(0)=0$ \\
\hline$y_{1}$ & Susceptible and sexually active men's population & $y_{1}(0)=600000$ \\
\hline$y_{2}$ & ZIKV positive men's population & $y_{2}(0)=5$ \\
\hline$z_{1}$ & $\begin{array}{c}\text { The non-carrier Aedes aegypti mosquitoes } \\
\text { population }\end{array}$ & $z_{1}(0)=100000$ \\
\hline$z_{2}$ & $\begin{array}{l}\text { The virus-carrier Aedes aegypti mosquitoes } \\
\text { population }\end{array}$ & $Z_{2}(0)=20$ \\
\hline$N$ & Total population $($ men + women $)$ & $N(0)=1000010$ \\
\hline$N_{1}$ & Total population of sexually active women & $N_{1}(0)=400010$ \\
\hline$N_{2}$ & Total population of sexually active men & $N_{2}(0)=600005$ \\
\hline$M$ & Total population of mosquitoes & $M(0)=100020$ \\
\hline
\end{tabular}

Table 2. Parameters of the simulation model.

\begin{tabular}{|c|c|c|}
\hline Parameter & Description & $\begin{array}{c}\text { Estimated/hypothetic } \\
\text { value }\end{array}$ \\
\hline$\Delta$ & $\begin{array}{l}\text { The fraction of women that get into the sexually active } \\
\text { population }\end{array}$ & 30 \\
\hline$\Phi$ & Men's fraction that get into the sexually active population & 20 \\
\hline$\mu$ & The natural mortality rate of persons & 0.0003 \\
\hline$g$ & $\begin{array}{l}\text { Infected pregnant women's fraction that are not } \\
\text { developing microcephaly }\end{array}$ & 0.1 \\
\hline $1-g$ & $\begin{array}{l}\text { Infected pregnant women's fraction that develops } \\
\text { microcephaly }\end{array}$ & 0.9 \\
\hline$\theta$ & Developing rate of the infection in the pregnant women & 0.7 \\
\hline$\beta$ & Transmission probability to the susceptible women & 0.7913 \\
\hline$\sigma$ & Probability of pregnancy & 0.6 \\
\hline$\alpha$ & The infected women recovery rate & 0.01 \\
\hline$h$ & Fraction of women that use contraceptive measures & $0.3,0.6,0.8$ \\
\hline$\delta$ & Transmission probability to the susceptible men & 0.7913 \\
\hline$\phi_{1}, \phi_{2}$ & Transmission probability to the non-carrier mosquitoes & $0.6,0.35$ \\
\hline$\epsilon$ & Death rate of the mosquitoes & 0.035 \\
\hline
\end{tabular}


In the flux diagrams of the Figures $1-3, \lambda_{1}(\cdot)=\sigma\left(\frac{y_{1}}{N_{2}}+\frac{y_{2}}{N_{2}}\right), \quad \lambda_{2}(\cdot)=\beta \frac{z_{2}}{M}$, $\lambda_{3}(\cdot)=\beta \frac{z_{2}}{M}, \quad \lambda_{4}(\cdot)=\gamma \frac{z_{2}}{M}$ $\lambda_{5}(\cdot)=\phi_{1} \frac{X_{3}}{N_{1}}+\phi_{2} \frac{x_{4}}{N_{1}}+\phi_{1} \frac{x_{5}}{N_{1}}+\phi_{1} \frac{y_{2}}{N_{2}}$.

The dynamic system in the sexually active women that get pregnant, susceptible to ZIKV as well as exposed to microcephaly are (according to Figure 1):

$$
\begin{gathered}
\frac{\mathrm{d} x_{1}(t)}{\mathrm{d} t}=\Delta-\sigma \frac{y_{1}(t)}{N_{2}(t)}(1-h) x_{1}(t)-\sigma \frac{y_{2}(t)}{N_{2}(t)}(1-h) x_{1}(t)-\beta \frac{z_{2}(t)}{M(t)} x_{1}(t)-\mu x_{1}(t) \\
\frac{\mathrm{d} x_{2}(t)}{\mathrm{d} t}=\sigma \frac{y_{1}(t)}{N_{2}(t)}(1-h) x_{1}(t)+\sigma \frac{y_{2}(t)}{N_{2}(t)}(1-h) x_{1}(t)-\beta \frac{z_{2}(t)}{M(t)} x_{2}(t)-\mu x_{2}(t) \\
\frac{\mathrm{d} x_{3}(t)}{\mathrm{d} t}=\beta \frac{z_{2}(t)}{M(t)} x_{2}(t)-(\theta+\mu) x_{3}(t) \\
\frac{\mathrm{d} x_{4}(t)}{\mathrm{d} t}=g \theta x_{3}(t)-\mu x_{4}(t) \\
\frac{\mathrm{d} x_{5}(t)}{\mathrm{d} t}=\beta \frac{z_{2}(t)}{M(t)} x_{1}(t)-(\alpha+\mu) x_{5}(t)
\end{gathered}
$$

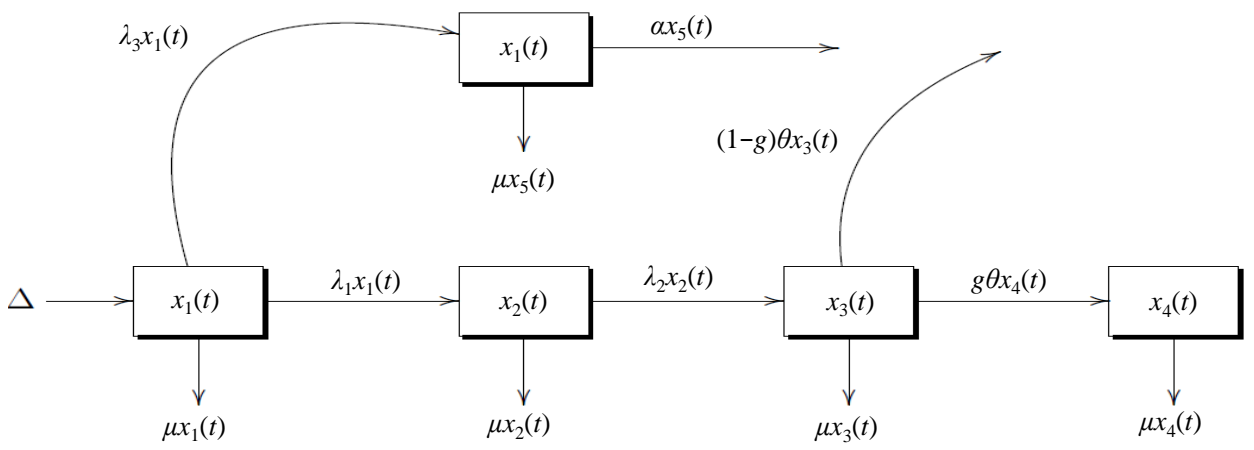

Figure 1. The dynamics of the pregnant women population.

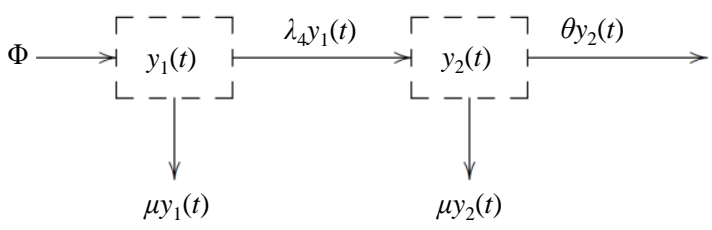

Figure 2. The dynamics of the sexually active men's population.

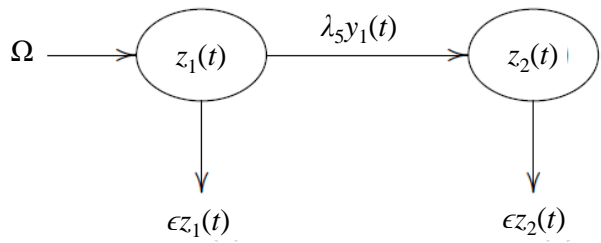

Figure 3. Dynamics of the Aedes aegypti mosquitoes population. 
In this system $\frac{\mathrm{d} x_{i}(t)}{\mathrm{d} t} ; i=1, \cdots, 5$ indicates the variation of each women population in time, these variations are defined as inflows minus outflows. The equations corresponding to the dynamics of the sexually active men that get infected by the virus-carrier mosquito bite are (according Figure 2):

$$
\begin{gathered}
\frac{\mathrm{d} y_{1}(t)}{\mathrm{d} t}=\Phi-\beta \frac{z_{2}(t)}{M(t)} y_{1}(t)-\mu y_{1}(t) \\
\frac{\mathrm{d} y_{2}(t)}{\mathrm{d} t}=\beta \frac{z_{2}(t)}{M(t)} y_{1}(t)-(\theta+\mu) y_{2}(t)
\end{gathered}
$$

From these equations (6) and (7) $\frac{\mathrm{d} y_{i}(t)}{\mathrm{d} t} ; i=1,2$, are the variations of each men's population in time, and are the result of inflows minus outflows. Finally, the equations belonging to the infectious process in the non-carrier and virus-carrier mosquitoes are (as shown in Figure 3):

$$
\begin{gathered}
\frac{\mathrm{d} z_{1}(t)}{\mathrm{d} t}=\Omega-\phi_{1} \frac{x_{3}(t)}{N_{1}(t)} z_{1}(t)-\phi_{2} \frac{x_{4}(t)}{N_{1}(t)} z_{1}(t)-\phi_{1} \frac{x_{5}(t)}{N_{1}(t)} z_{1}(t)-\phi_{1} \frac{y_{2}(t)}{N_{2}(t)} z_{1}(t)-\epsilon z_{1}(t) \\
\frac{\mathrm{d} z_{2}(t)}{\mathrm{d} t}=\phi_{1} \frac{x_{3}(t)}{N_{1}(t)} z_{1}(t)+\phi_{2} \frac{x_{4}(t)}{N_{1}(t)} z_{1}(t)+\phi_{1} \frac{x_{5}(t)}{N_{1}(t)} z_{1}(t)+\phi_{1} \frac{y_{2}(t)}{N_{2}(t)} z_{1}(t)-\epsilon z_{2}(t)
\end{gathered}
$$

In a similar way, Equations (8) and (9) are result of inflows and outflows.

The variation in time of each total population $N_{1}(t), N_{2}(t), N(t)$ and $M(t)$ is defined by the following differential equations:

$$
\begin{aligned}
& N_{1}(t)=\sum_{i=1}^{5} x_{i}(t) \\
& \frac{\mathrm{d} N_{1}(t)}{\mathrm{d} t}=\sum_{i=1}^{5} \frac{\mathrm{d} x_{i}(t)}{\mathrm{d} t}
\end{aligned}
$$

As well,

$$
\begin{aligned}
& N_{2}(t)=\sum_{j=1}^{2} y_{j}(t) \\
& \frac{\mathrm{d} N_{2}(t)}{\mathrm{d} t}=\sum_{j=1}^{2} \frac{\mathrm{d} y_{j}(t)}{\mathrm{d} t}
\end{aligned}
$$

Then, $N(t)=N_{1}(t)+N_{2}(t)$.

Varying with respect to $t$, it is obtained

$$
\frac{\mathrm{d} N(t)}{\mathrm{d} t}=\sum_{i=1}^{5} \frac{\mathrm{d} x_{i}(t)}{\mathrm{d} t}+\sum_{j=1}^{2} \frac{\mathrm{d} y_{j}(t)}{\mathrm{d} t}
$$

In the case of mosquitoes,

$$
M(t)=\sum_{k=1}^{2} z_{k}(t)
$$

Varying in function of $t$,

$$
\frac{\mathrm{d} M(t)}{\mathrm{d} t}=\sum_{k=1}^{2} \frac{\mathrm{d} z_{k}(t)}{\mathrm{d} t}
$$

From the dynamic systems, replacing the equations (1)-(7) in (10)-(13), it is obtained the dynamic system of the populations, 


$$
\begin{gathered}
\frac{\mathrm{d} N_{1}(t)}{\mathrm{d} t}=\Delta-\mu N_{1}(t)-\theta x_{3}(t)-\alpha x_{5}(t)+g \theta x_{3}(t) \\
\frac{\mathrm{d} N_{2}(t)}{\mathrm{d} t}=\phi-\mu N_{2}(t)-\theta y_{2}(t) \\
\frac{\mathrm{d} N(t)}{\mathrm{d} t}=\Delta+\phi-\mu N(t)-\theta x_{3}(t)-\alpha x_{5}(t)-\theta y_{2}(t)+g \theta x_{3}(t) \\
\frac{\mathrm{d} M(t)}{\mathrm{d} t}=\Omega-\epsilon M(t)
\end{gathered}
$$

\section{Simulations and Results}

The dynamic systems (1)-(5), (6)-(9) were simulated using the Maple software, with the values of Table 1 and Table 2.

In Figure 4 it is indicated that with an $80 \%$ of women under contraceptive protection, the populations of susceptible pregnant women, the infected ones and men infected with ZIKV tend to stabilize in an average time of 40 days. These populations have a maximum point in an average of 10 days and having a lower number of infections through time. Moreover, the infected pregnant women with no microcephaly present a significant increase and tend to rise slowly through the time. This can be explained through a recent report by Cauchemez et al. (2016) [18] where they have estimated that the risk of microcephaly increase approximately $1 \backslash \%$ when the pregnant women are infected by ZIKV in the first trimester. According to this fact, it is possible to corroborate the increase of infected women that do not develop microcephaly, associating the ZIKV with a low fetal risk. Figure 5 depicts different levels of $h$ (women's

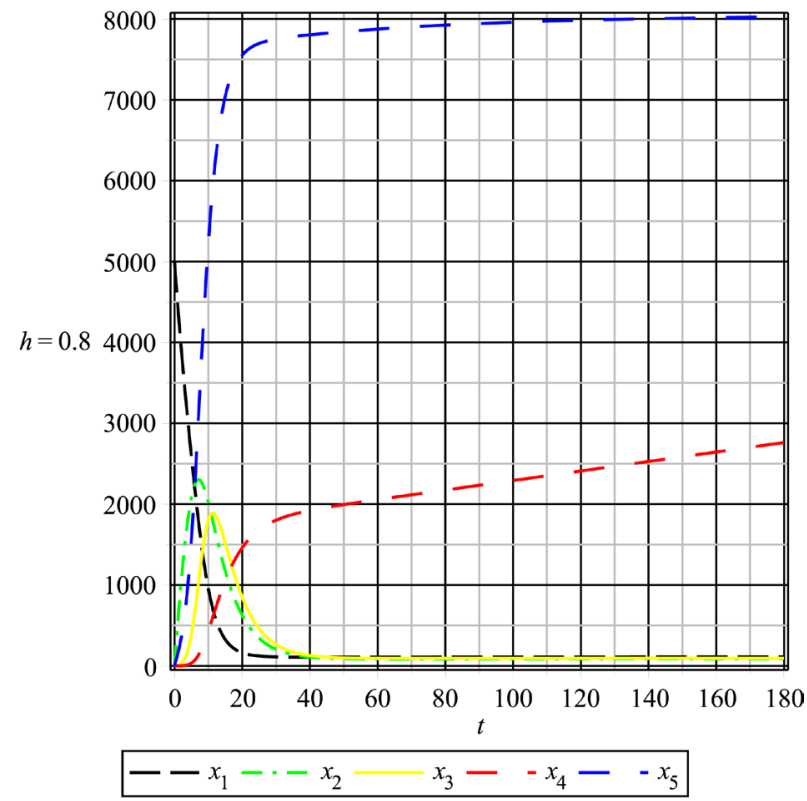

Figure 4. Behavior of the susceptible pregnant women, infected pregnant women, infected women without microcephaly development, and ZIKV infected men. 

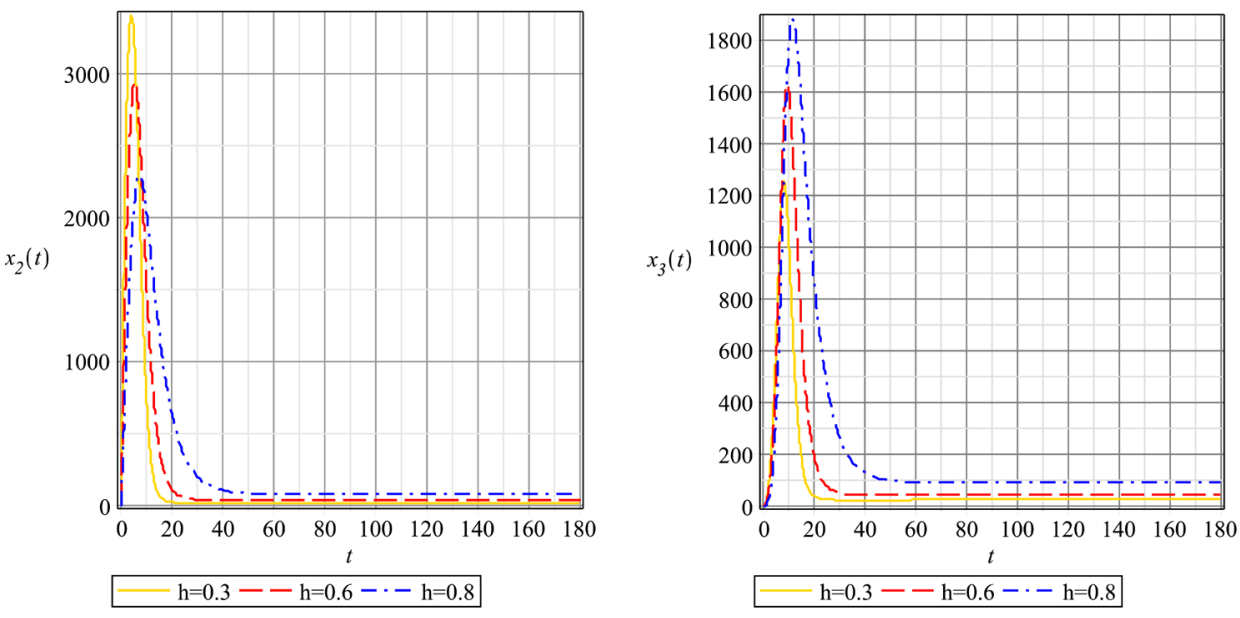

Figure 5 . The susceptible $\mathrm{x}_{2}$ and infected $\mathrm{x}_{3}$ pregnant women's behavior.

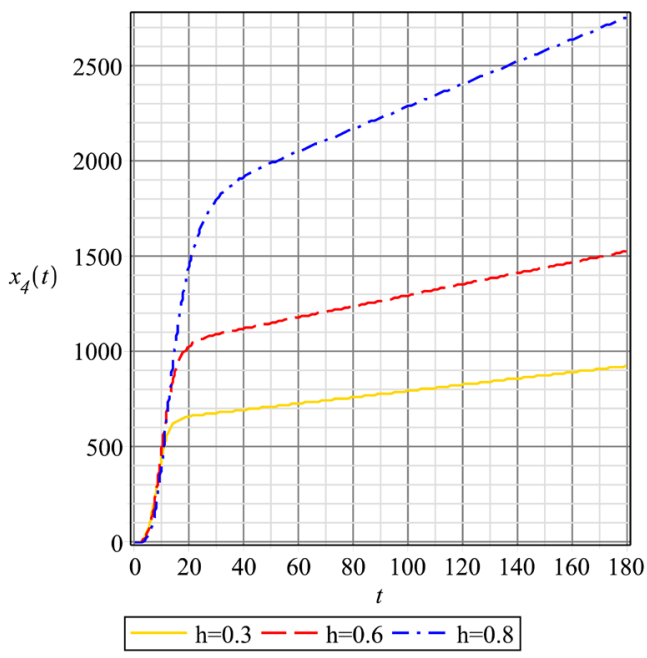

Figure 6. Infected pregnant women that do not develop microcephaly.

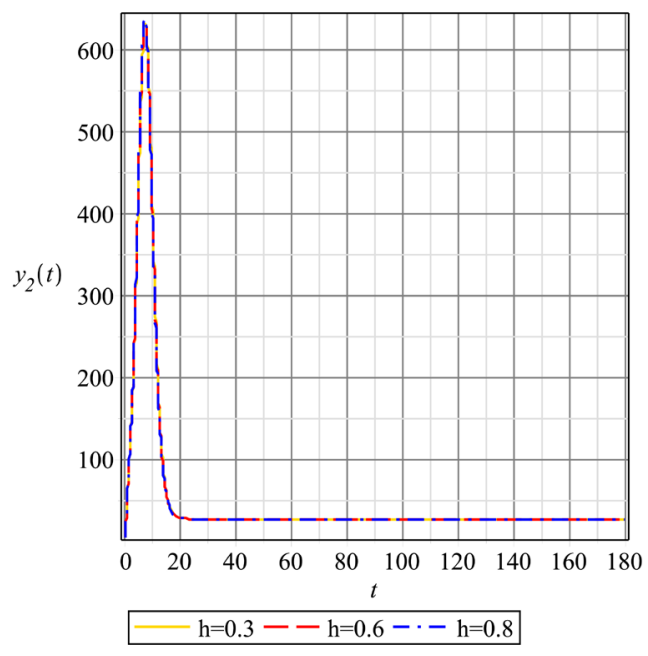

Figure 7. ZIKV infected men's population. 
fraction under contraceptive protection). The behavior of the susceptible pregnant women population rise showing a maximum point that is each time smaller as $h$ increases, namely, with the contraceptive measures, the susceptible women population decreases. A similar behavior is presented by the infected pregnant women. Both populations tend to stabilize in an average of 35 days.

The pregnant women's population that develops microcephaly have a quick growth till almost 25 days, after that, the population tends to have a linear-like growth through time as $h$ increases. However, this population has a maximum point when $h=0.8$ see Figure 6.

Figure 7 shows that the infected men's population rises quickly in an average of 10 days, after 20 days decreases and tends to stabilize. This population does not change through time when the fraction of women that are under contraceptive treatments rises.

\section{Conclusions}

The behavior of the simulations shows that the susceptible pregnant women's population is sensitive to the women's fraction under birth control. This is an expected result if we account for an $80 \%$ of this fraction, were the susceptible women, infected pregnant women and women without microcephaly development population's decrease. With this model it is possible to make predictions and analysis to design more effective strategies in the future.

ZIKV has a little known natural history, then, it is primordial to generate new mathematical studies to gain a better understanding of this disease and propose effective control strategies.

The proposed model in this paper can be applied (with the respective adjustments) in the study of other viral infections transmitted by vectors that generate risk of other pathological complications.

\section{Acknowledgements}

AML thanks to Grupo de Modelación Matemática en Epidemiología (GMME), Facultad de Educaciónl’on, Universidad del Quindío-Colombia.

\section{References}

[1] Liu-Helmersson, J., Stenlund, H., Wilder-Smith, A. and Rocklov, J. (2014) Vectorial Capacity of Aedes aegypti: Effects of Temperature and Implications for Global Dengue Epidemic Potential. PLOS ONE, 9, e89783.

[2] Polwiang, S. (2015) The Seasonal Reproduction Number of Dengue Fever: Impacts of Climate to Transmission. Department of Mathematics, Faculty of Science, Silpakorn University, Thailandia.

[3] Dick, G.W., Cocina, S.F. and Haddow, A.J. (1952) Zika aislamientos de virus y especificidad serológica. Transactions of The Royal Society of Tropical Medicine and Hygiene, 46, 509-520. http://dx.doi.org/10.1016/0035-9203(52)90042-4

[4] Dick, G.W. (1952) Patogenicidad del virus y propiedades fisicas Zika. Transactions of The Royal Society of Tropical Medicine and Hygiene, 46, 521-534. 
http://dx.doi.org/10.1016/0035-9203(52)90043-6

[5] Haddow, A.D., Schuh, A.J., Yasuda, C.Y., Kasper, M.R., Fleang, V., FHuy, R., Guzman, F.I., Tesh, R.B. and Weaver, S.C. (2012) Genetic Characterization of Zika Virus Strains: Geographic Expansion of the Asian Lineage. PLOS Neglected Tropical Diseases, 6, e1477.

[6] Faye, O., Faye, O., Diallo, D., Diallo, M., Weidmann, M. and Sail, A.A. (2013) Quantitative Real-Time PCR Detection of Zika Virus and Evaluation with Field-Caught Mosquitoes. Virology Journal, 10, 311.

[7] Baronti, C., Piorkowski, G., Charrel, R.N., Boubis, L., Leparc-Goffart, I. and de Lamballerie, X. (2014) Complete coding sequence of zika virus from a French Polynesia outbreak in 2013. Genome Announcements, 2, pii: e00500-14.

[8] Cabrera Pérez, Z. (2014) Epidemiologia del virus Zika. Universidad Veracruzana.

[9] Heang, V., Yasuda, C.Y., Sovann, L., Haddow, A.D., Travassos da Rosa, A.P., Tesh, R.B., et al. (2012) Zika Virus Infection, Cambodia, 2010. Emerging Infectious Diseases, 18, 1-3. http://dx.doi.org/10.3201/eid1802.111224

[10] Kwong, J.C., Druce, J.D. and Leder, K. (2013) Zika Virus Infection Acquired during Brief Travel to Indonesia. The American Journal of Tropical Medicine and Hygiene, 89, 516-517. http://dx.doi.org/10.4269/ajtmh.13-0029

[11] Pouliot, S.H., Xiong, X., Harville, E., Paz-Soldan, V., Tomashek, K.M., Breart, G., et al. (2010) Maternal Dengue and Pregnancy Outcomes: A Systematic Review. Obstetrical \& Gynecological Survey, 65, 107-118.

[12] Wong, P.S., Li, M.Z., Chong, C.S., Ng, L.C. and Tan, C.H. (2013) Aedes (Stegomyia) albopictus (Skuse): A Potential Vector of Zika Virus in Singapore. PLOS Neglected Tropical Diseases, 7, e2348.

[13] European Centre for Disease Prevention and Control (2015) Rapid Risk Assessment: Microcephalyin Brazil Potentially Linked to the Zika Virus Epidemic, 24 November 2015. ECDC, Stockholm.

[14] Peñas, J.J. and Andl'ujar, F.R. (2003) Alteraciones del perímetro craneal: Microcefalia y macrocefalia. Pediatr Integral, 7, 587-600.

[15] Daozhou, G., Yijun, L., Daihai, H., Travis, C.P., Yangk, K., Gerardo, Ch. and Shigui, R. (2016) Prevention and Control of Zika as a Mosquito-Borne and Sexually Transmitted Disease: A Mathematical Modelling Analysis. Scientific Reports, 6, 28070.

[16] Nishiura, H., Kinoshita, R., Mizumoto, K., Yasuda, Y. and Nah, K. (2016) Transmission Potential of Zika Virus Infection in the South Pacific. International Journal of Infectious Diseases, 45, 95-97. http://dx.doi.org/10.1016/j.ijid.2016.02.017

[17] Pizza, D.M.M., Loaiza, A.M., Montoya, J.F.A., Manrique, O.A., Sossa, V.A., Muñoz, C.A.A., Raigosa, S.,Contreras, H.M., Contreras, I.P., Perea, M.E.C. and Enríquez, M.A. (2016) A Model for the Risk of Microcephaly Induced by the Zika Virus (ZIKV). Open Journal of Modelling and Simulation, 4, 109-117. http://dx.doi.org/10.4236/ojmsi.2016.43010

[18] Cauchemez, S., Besnard, M., Bompard, P., Dub, T., Guillemette-Artur, P., Eyrolle-Guignot, D., Salje, H., Van Kerkhove, M.D., Abadie, V., Garel, C., Fontanet, A. and Mallet, H.-P. (2016) Association between Zika Virus and Microcephaly in French Polynesia, 2013-15: A Retrospective Study. The Lancet, 387, 2125-2132. http://dx.doi.org/10.1016/S0140-6736(16)00651-6 